\title{
AN INTERESTING CASE OF EPILEPSY IN A 3 YEAR OLD FOLLOWING TRUMATIC BRAIN INJURY WITH THE METAL ROD
}

Japnit Singh¹, V. D. Aironi², Ashutosh Chitnis³ ${ }^{3}$ Rajiv Hira ${ }^{4}$

\section{HOW TO CITE THIS ARTICLE:}

Japnit Singh, V. D. Aironi, Ashutosh Chitnis, Rajiv Hira. "An Interesting Case of Epilepsy in a 3 Years Old Following Trumatic Brain Injury with the Metal Rod". Journal of Evolution of Medical and Dental Sciences 2015; Vol. 4, Issue 60, July 27; Page: 10577-10583, DOI: 10.14260/jemds/2015/1527

ABSTRACT: Post-traumatic epilepsy (PTE) results from injury to the brain and presents as a recurrent seizure disorder. ${ }^{1}$ this injury may be due to traumatic brain injury (TBI) or to an operation on the brain. Here we discuss a case of a 3 year old male child who presented with left sided deviation of the neck along with frothing from the mouth and a staring gaze. The child had a history of penetrating injury 6 months back with a metal rod which entered through the frontal bone after he fell on a railway track. At that time, the rod was removed followed by a CT scan and no major intervention was done.

KEYWORDS: Epilepsy, Trauma, Post-Traumatic, Traumatic Brain Injury, PTS, PTE, TBI.

INTRODUCTION: Head trauma is very common in today's world. Severe head trauma can be defined as either loss of consciousness or amnesia for greater than a day or internal bleeding in or around the brain. Severe head trauma leads to epilepsy in about $15 \%$ of adults and about $30 \%$ of children. Essentially, PTE must be differentiated from posttraumatic seizures (PTS), which is a broaderspectrum term and signifies seizures that occur as a sequel to brain injury. Post-Traumatic epilepsy can occur soon after injury or may develop months to years later. Immediate PTS occurs within 24 hours, early PTS occurs within 1 week ad late PTS occurs more than 1 week after the injury. About $20 \%$ of people who have a single late PTS never have any further seizures, and these people should not be labeled as having PTE. Recurrent late PTS is termed as PTE.

CASE REPORT: Here we report a case of a 3 years old male patient who presented with a history of deviation of the neck to the left along with staring gaze and frothing from mouth. The patient had a previous history of a penetrating injury to the head 6 months back wherein a metal rod had penetrated his head at the frontal bone after he fell on a railway track. He was taken to a private hospital then where they removed the rod and the CT done then showed evidence of left frontal lobe contusion. No major intervention was done at that time.

ON EXAMINATION: At the time of presentation the patient was calm, conscious, alert, and afebrile with no evidence of any meningeal signs. Systemic examination was also normal.

INVESTIGATIONS: The patient was further taken up for routine investigations which were all within normal range. EEG examination was done which also came out to be normal.

\section{MRI WAS DONE FOR THE PATIENT, TO ASSESS THE CAUSE OF EPILEPSY AND SHOWS:}

Fig. 1: An axial T2WI of the patient at the level of the midbrain shows a $4.2 \times 1.9 \mathrm{~cm}$ hyper intense CSF intensity gliotic defect in the left frontal region.

Fig. 2(A): On T1 WI the hyperintensity seen in the previous image is hypo intense.

Fig. 2(B): Is a FLAIR sequence that also gives a hypointense signal in the region of the lesion. 


\section{CASE REPORT}

Fig. 3: Coronal section in a FLAIR sequence shows that the defect is in left basi-frontal region and is extending into left para-falcine region medially and inferiorly towards right side along the cribriform plate.

Fig. 4: CT confirms the presence of bony defect.

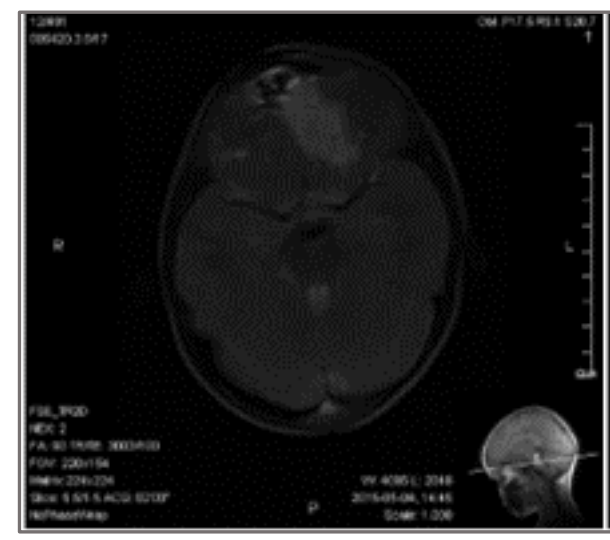

Fig. 1

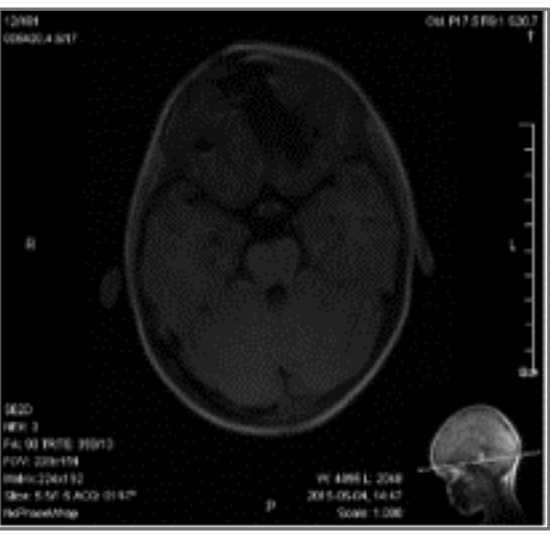

Fig. 2(A)

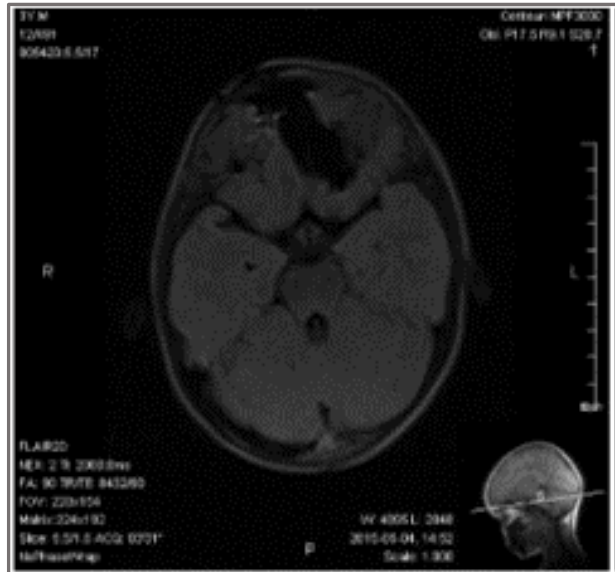

Fig. 2 (B)

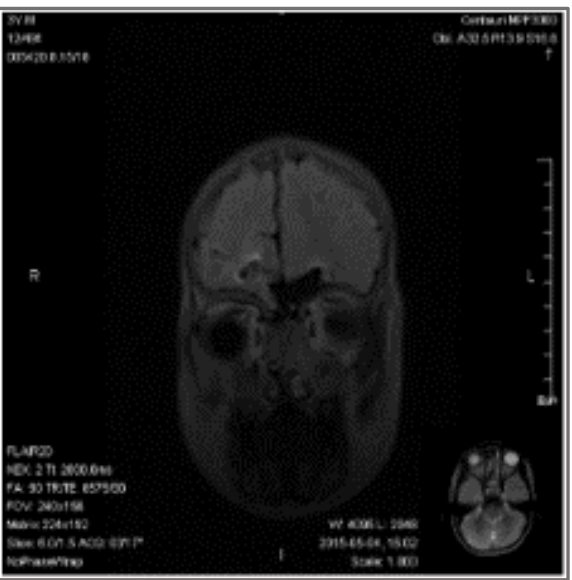

Fig. 3

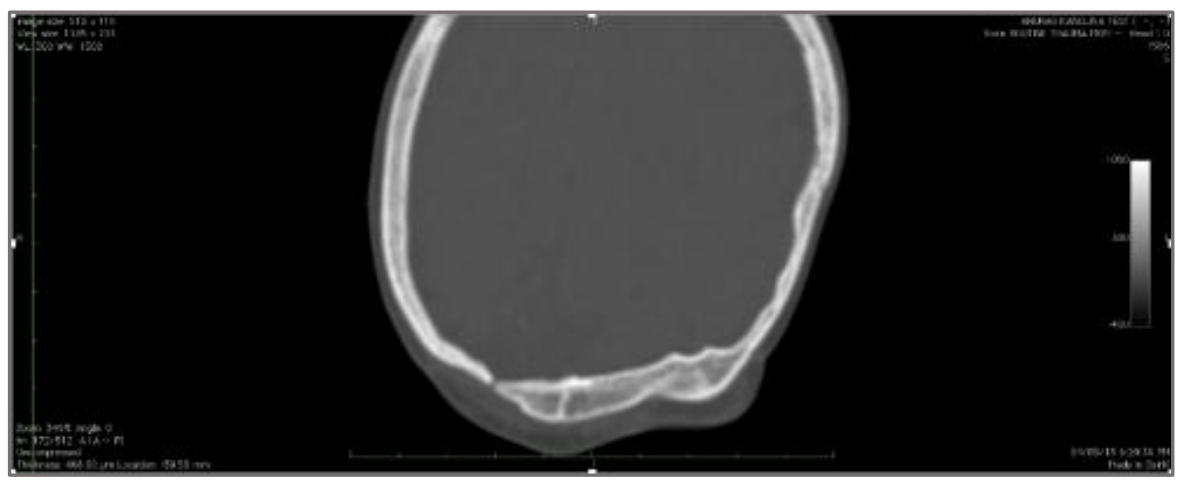

Fig. 4 


\section{CASE REPORT}

Fig. 5: T2 WI Shows old post traumatic gliotic scars in the right frontal region as hyperintensities. Fig. 6: T1 WI Shows an isointense area corresponding to the hyperinetsities in the previous image. Fig. 7: Flair sequence shows hyperintensities in the right frontal region, indicating old post traumatic gliotic scars. Also areas of cortical thickening are seen.

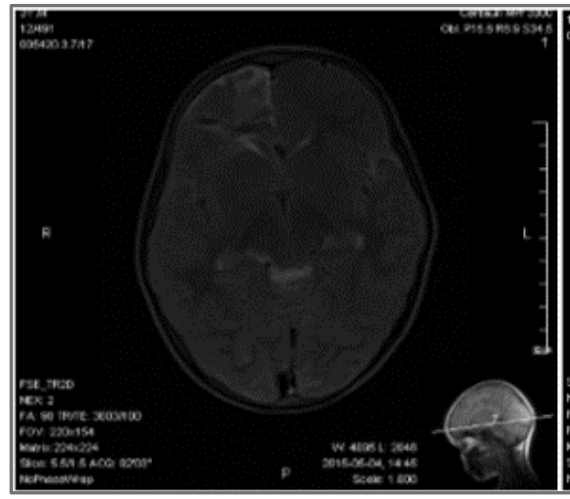

Fig. 5

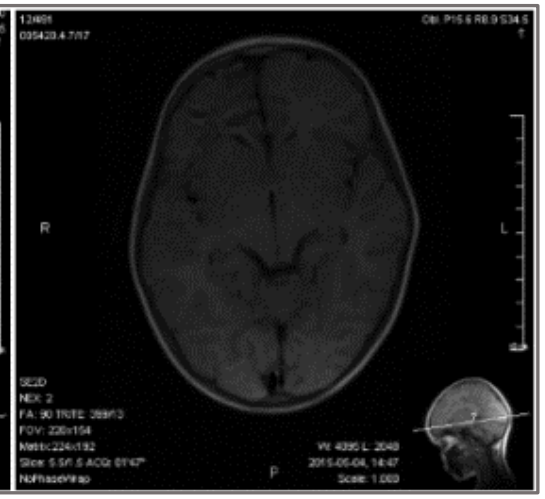

Fig. 6

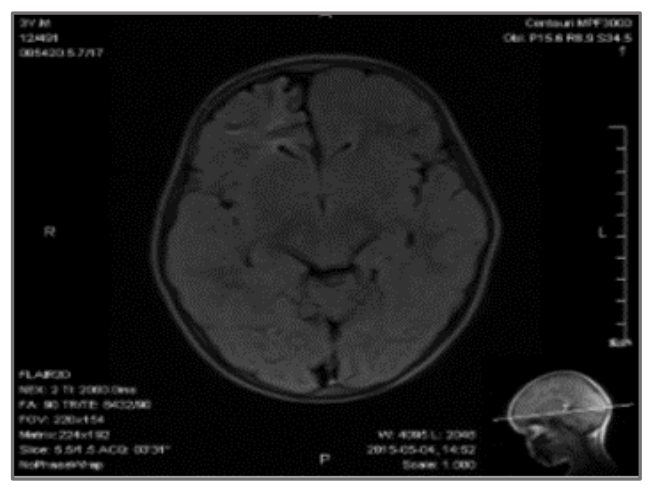

Fig. 7

T2 WI (Fig. 8, 11) and flair (Fig. 10) shows heterointense old post traumatic gliotic scars in the right frontal region. These areas are hypointense on T1 WI (Fig. 9)

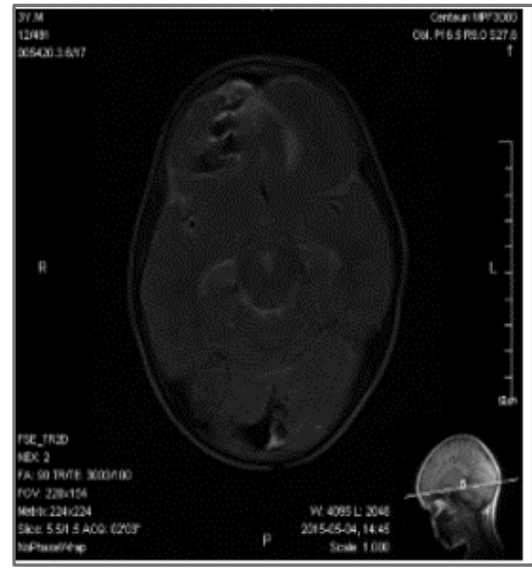

Fig. 8

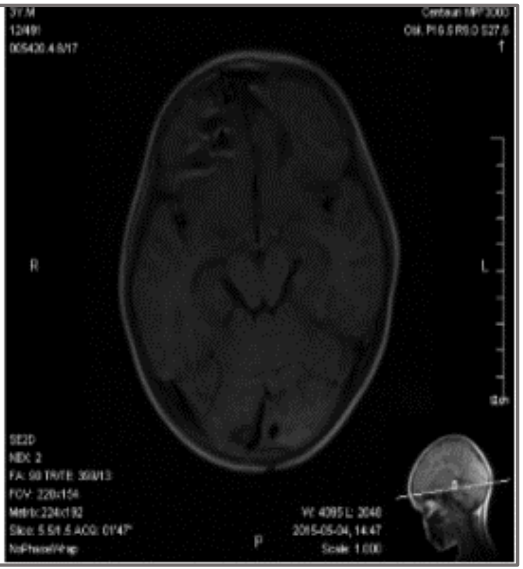

Fig. 9 


\section{CASE REPORT}

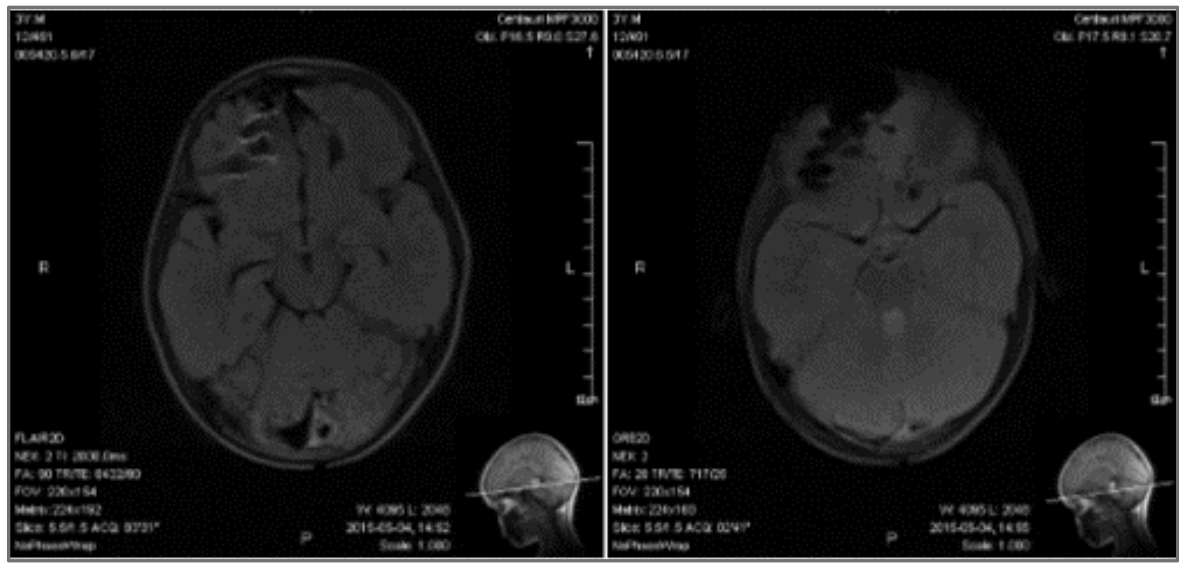

Fig. 10

Fig. 11

Fig. 12 (A, B): CT Scan Rules Out Presence Of Pneumocephalus And Confirms Gliotic Scarring:

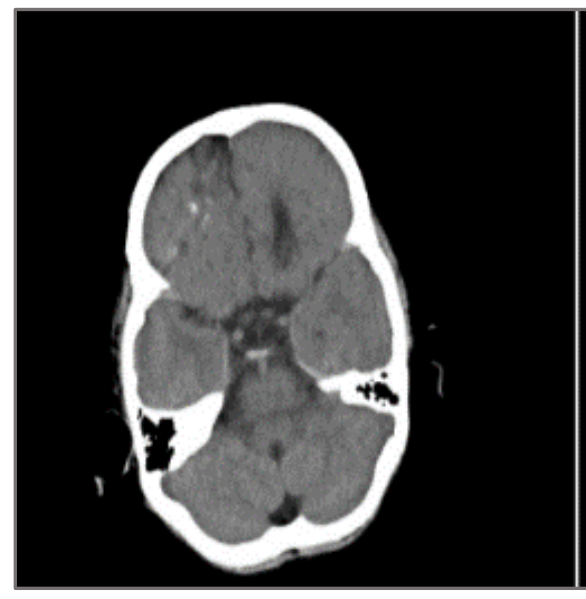

Fig. $12(A)$

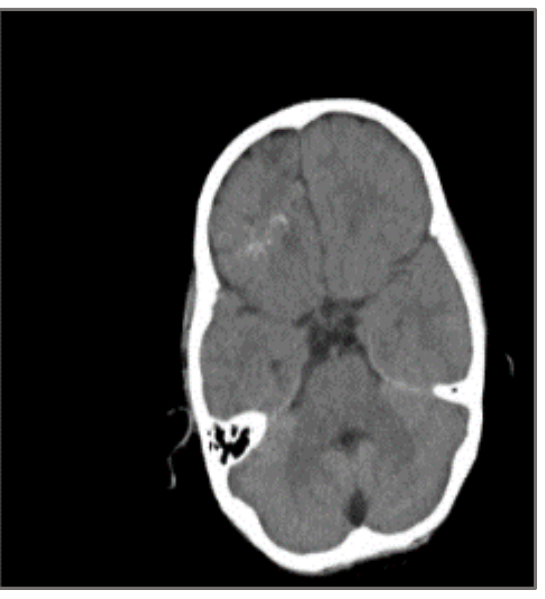

Fig. 12 (B)

Fig.13 (A-C): Shows that there is no restriction on dwi:

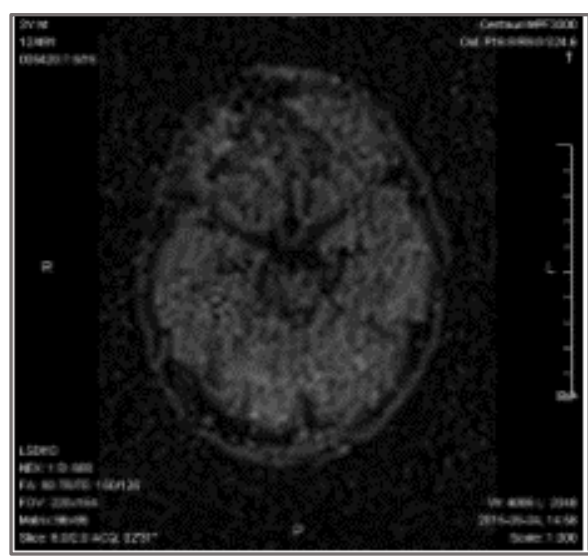

Fig. 13 (A)

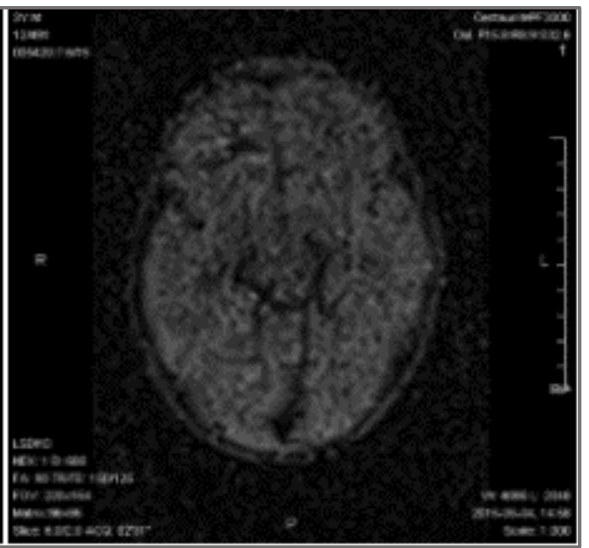

Fig. 13 (B) 


\section{CASE REPORT}

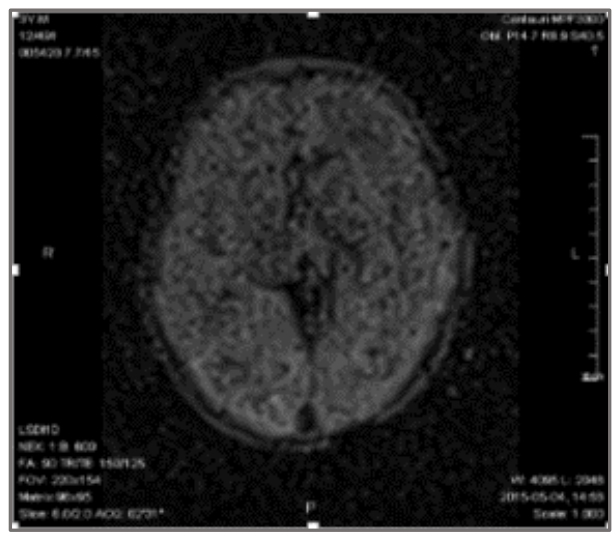

Fig. 13 (B)

Fig. 14 (A, B): Mesial Temporal Lobe Appears Normal and Rules Out Other Causes Of Epilepsy.

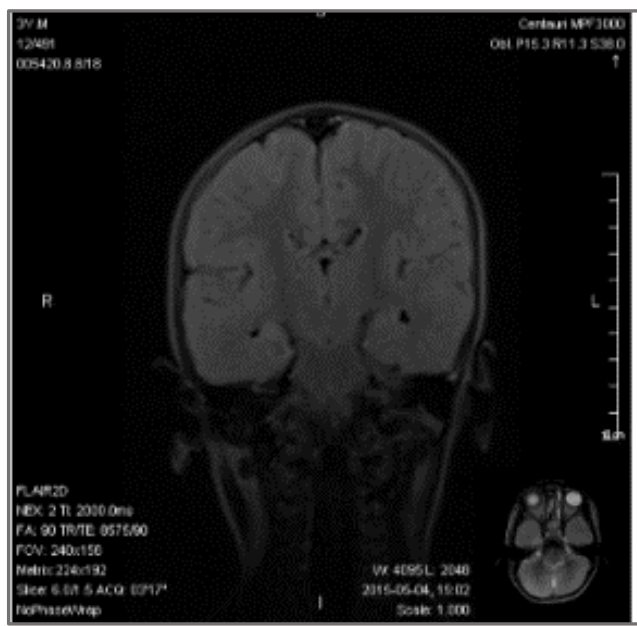

Fig. 14 (A)

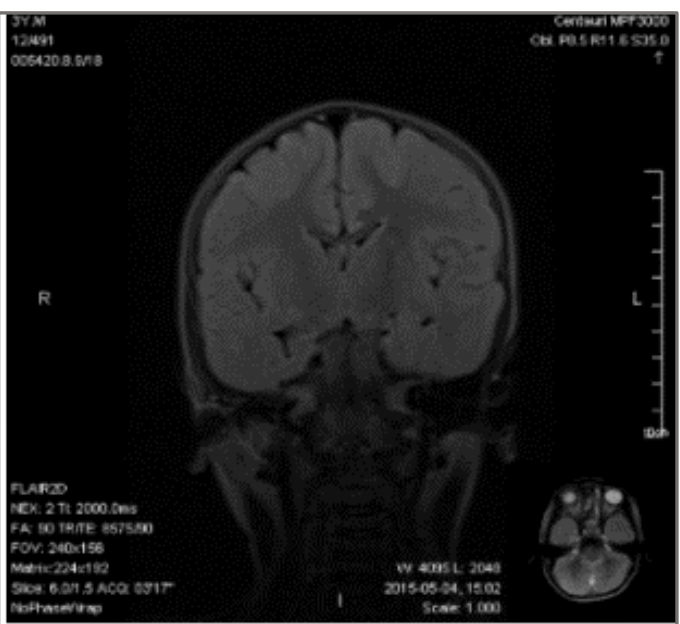

Fig. 14 (B)

DISCUSSION: The cause in 5\% of all epilepsy patients and $20 \%$ of all symptomatic epilepsy patients is Traumatic brain injury (TBI). ${ }^{2}$ Seizures are broadly classified as early or late, following head injury. Early seizures (i.e., within one to two weeks after injury) are acute seizures that occur as a result of the physical effects of the trauma. Late seizures occur after the patient has recovered from the effects of the injury and can occur weeks, months, or even years after the original injury. ${ }^{2}$ Late PTS can be a single or recurrent event and recurrent late seizures are termed as post-traumatic epilepsy. ${ }^{3}$

The type and severity of head injury also play a role in determining the risk of developing epilepsy afterwards. With non-penetrating head injuries, the first late seizure occurs within the first year in $60 \%$ of individuals. ${ }^{3}$ Depressed skull fractures and intracranial hematomas are associated with increased risk of late seizure due to the presence of blood or blood degradation products. ${ }^{3,4}$ Various theories explain the cause of post-traumatic epilepsy due to blood such as the formation of free radicals by the blood breakdown product iron which cause direct injury to neuronal membranes and cell death and another theory which shows that blood breakdown product Hemin affects synaptic transmission and leads to epileptogenesis. ${ }^{5,6}$ 
Early Post-traumatic seizures commonly present as generalized tonic-clonic seizures while late post-traumatic seizures and post-traumatic epilepsy commonly present with either simple or complex partial seizures which may lead to secondarily generalized seizures. General absence seizures are not normally caused by head injury.7,8,9

Patients that arrive with moderate or severe head injury should be imaged with a CT scan immediately, and the study should be repeated if the condition of the patient does not improve. ${ }^{10}$ It is readily available, fast, and usually very accurate at detecting acute hemorrhage (High density on unenhanced scan) and depressed skull fractures. Imaging should also be repeated in cases of mild head injury complicated with a seizure or unexpected event (e.g., such as an acute change in mental status) during the course of patient recovery. EEG (electroencephalogram) has only a limited role in evaluating patients with early post-traumatic seizures who are experiencing intermittent behavioral changes.

It is not useful in predicting the development of post-traumatic epilepsy. Overall, MRI reveals the extent of brain damage after head trauma with greater sensitivity than CT. The presence of cortical or subcortical hyper intense lesions visible on T2WI with accompanying hemosiderin on GRE sequences is associated with an increased risk of PTE. ${ }^{11}$ SWI is frequently utilized for the detection of blood products in the patient with PTE and no apparent abnormalities in other MRI sequences. Thus, we see that Neuroimaging has provided an extraordinary insight into the pathologic substrate of epilepsy, which is essential for diagnosis, treatment, and determination of prognosis in epileptic patients. MRI is the primary imaging modality for the evaluation of patients with seizures and is very useful for evaluating the various sequelae of TBI. Finally, the patient was discharged on Tab. Oxycarbmezapine following which the patient has not had any new episodes of epilepsy.

\section{REFERENCES:}

1. Hunt RF, Boychuk JA, Smith BN. Neural circuit mechanisms of post-traumatic epilepsy. Front Cell Neurosci. 2013. 7:89.

2. Hauser WA, Annegers JF, Kurland LT. Prevalence of epilepsy in Rochester, Minnesota: 19401980.Epilepsia. 1991; 32:429-445.

3. Langendorf, F. and Pedley, T. A. (1997) Epilepsy: A Comprehensive Textbook. Lippincott-Raven, Philadelphia.

4. Adams, R. D., Victor, M., and Ropper, A. H. (1997) Craniocerebral Trauma. In: Principles of Neurology. 6th Edition. McGraw-Hill, New York. pp. 874-889.

5. Yip, S. and Sastry, B.R. (2000) "Effects of hemoglobin and its breakdown products on synaptic transmission in rat hippocampal CA1 neurons", Brain Res. 864, 1-12.

6. Kandel, E. R. and Siegelbaum, S. A. (2000) Synaptic Integration. In: Principles of Neuroscience. 4th Edition. Kandel, E. R., Schwartz, J. H. and Jessell, T. M. (eds.), McGraw-Hill, New York. pp. 219-221.

7. Annegers, J. F., Hauser, A., Coan, S. P., and Rocca, W. A. (1998) A population based study of seizures after traumatic brain injuries. N. Engl. J. Med. 338:20-24.

8. Evans, J.H. (1962) Post-traumatic epilepsy. Neurol. 12:665-674.

9. Salazar, A. M., Jabbari, B., Vance, S. C., Grafman, J., Amin, D., and Dillon, J. D. (1985) Epilepsy after penetrating head injury. I. Clinical correlates: a report of the Vietnam Head Injury. Study. Neurol. 35:1406-1414. 


\section{CASE REPORT}

10. Grossman RI, Yousem DM. Head Trauma. In: Thrall JH, ed. Neuroradiology: The Requisites. Philadelphia, PA: Elsevier; 2003:243-246.

11. Angeleri F, Majkowski J, Cacchiò G, et al. Posttraumatic epilepsy risk factors: one-year prospective study after head injury. Epilepsia 1999; 40(9):1222-1230.

\section{AUTHORS: \\ 1. Japnit Singh \\ 2. V. D. Aironi \\ 3. Ashutosh Chitnis \\ 4. Rajiv Hira}

\section{PARTICULARS OF CONTRIBUTORS:}

1. Resident, Department of Radiology, MGM Hospital, Kamothe, Navi Mumbai.

2. Associate Professor, Department of Radiology, MGM Hospital, Kamothe, Navi Mumbai.

3. Associate Professor, Department of Radiology, MGM Hospital, Kamothe, Navi Mumbai.

FINANCIAL OR OTHER COMPETING INTERESTS: None
4. Resident, Department of Radiology, MGM Hospital, Kamothe, Navi Mumbai.

\section{NAME ADDRESS EMAIL ID OF THE CORRESPONDING AUTHOR:}

Japnit Singh, \#503, PG Hostel, MGM Hospital, Kamothe, Navi Mumbai-410209, India.

Email: japosingh@gmail.com

Date of Submission: 06/07/2015. Date of Peer Review: 07/07/2015. Date of Acceptance: 21/07/2015. Date of Publishing: 27/07/2015. 